\title{
COPD (confusion over proper diagnosis) in the zone of maximum uncertainty
}

\begin{abstract}
To the Editor:
In an excellent statement on chronic obstructive lung disease (COPD) that focuses on questions that are relevant for the patient's well-being and quality of life $[1,2]$, one issue should have received more critical attention. For research into COPD, it is vital that the diagnosis of airway obstruction, which traditionally hinges on a forced expiratory volume in $1 \mathrm{~s}$ (FEV1)/forced vital capacity (FVC) ratio below a threshold, can be accurately established. CelLi et al. $[1,2]$ state that this threshold is uncertain, leaving the recommendations open ended to some extent. They refer to the discussion whether in ascertaining a diagnosis of COPD the threshold for the FEV1/FVC ratio should be the lower limit of normal (LLN), defined in respiratory medicine as the 5th centile in a representative sample of healthy nonsmokers, or the post-bronchodilator FEV1/FVC of 0.7 first proposed in 2001 by the Global Initiative for Chronic Obstructive Lung Disease (GOLD) group [3]. The latter threshold has not been clinically validated; it was intended to simplify recognition and increase awareness of COPD, particularly in less developed countries where the LLN might not be presented with the test results. The use of the fixed ratio has been extensively criticised. Cross-sectional data show that it leads to underestimating the prevalence of airflow limitation in younger people and to large overestimates in those older than 45 years. In 80 -year-old healthy subjects, this leads to a $75-80 \%$ false positive rate [4]. The Burden of Obstructive Lung Disease (BOLD) group also routinely uses the LLN cut-off for reporting the prevalence of abnormal ventilatory function [5]. Follow-up studies have shed light on the question of whether observations in the zone between the fixed ratio and LLN represent respiratory disease. In asymptomatic subjects and very elderly subjects, an FEV1/ FVC above the LLN but below 0.7 was not associated with premature death [6-10], an abnormal decline in FEV1 [11-13], respiratory care use [11], hospitalisation [10] or quality of life [11]. Conversely, an FEV1/ FVC ratio below the LLN is associated with increased risk of hospitalisation [10] and mortality $[8-10,12$, 13]. Three reports $[9,16,17]$ suggested that use of the LLN cut-off would miss individuals at risk, but these findings have been contested [18-21].
\end{abstract}

In a discussion of a diagnostic test that establishes disease, it is important to note that clinical decisions often require a three-zone interpretation of "present", "absent" or "uncertain", rather than yes versus no [21]. Uncertainty may persist in a proportion of patients who have results that lie just above or below diagnostic thresholds, the zone of maximum uncertainty, thus requiring clinical judgment. The LLN approach facilitates clinical judgment by better distinguishing aging related changes in lung function from COPD related airflow obstruction, whereas GOLD criteria impede clinical judgment by applying a fixed ratio threshold across all ages [23].

There is overwhelming evidence that, unlike the LLN, the fixed ratio as a cut-off value is an inappropriate criterion for including or excluding subjects in COPD research projects, and will bias the findings. The American Thoracic Society (ATS) and European Respiratory Society (ERS) have previously agreed that the LLN is the proper diagnostic criterion for airflow limitation [24]. The present document $[1,2]$ re-introduces confusion on diagnostic criteria and therefore does not indicate a clear route for research into COPD using the best target group. The confusion first arose 14 years ago from an effort to simplify the diagnosis of airflow limitation when people might not have an appropriate LLN at their disposal. Now even small hand-held spirometers provide that information, so there is no justification for a rule of thumb which leads to so much misclassification in people below middle-age and old people, particularly in a world where more people are living longer [25]. Therefore, we ask the ATS, ERS, British Thoracic Society, National Institute for Care Excellence and other international and national respiratory organisations to carefully review all the evidence, and end the present confusion by issuing an unequivocal guideline. It's one of the great strengths of science that it can fix its own mistakes: let us do it now.

$@$ ERSpublications

A A fixed cut-off in FEV1/FVC ratio is not an appropriate measure for diagnosing COPD http://ow.ly/RZyLe

Philip H. Quanjer ${ }^{1}$, Gregg Ruppel ${ }^{2}$, Vito Brusasco $^{3}$, Rogelio Pérez-Padilla ${ }^{4}$, Carlos A. Vaz Fragoso ${ }^{5}$, Bruce H. Culver ${ }^{6}$, Maureen P. Swanney ${ }^{7}$, Martin R. Miller ${ }^{8}$, Bruce Thompson', Mike Morgan ${ }^{10}$, Mike Hughes ${ }^{11}$, Brian L. Graham ${ }^{12}$, Riccardo Pellegrino ${ }^{13}$, Paul Enright ${ }^{14}$, A. Sonia Buist ${ }^{15}$ and Peter Burney $^{16}$ 
${ }^{1}$ Dept of Pulmonary Diseases and Department of Paediatrics-Pulmonary Diseases, Erasmus Medical Centre, Erasmus University, Rotterdam, The Netherlands. ${ }^{2}$ Pulmonary Function Laboratory, Saint Louis University Hospital, St Louis, MO, USA. ${ }^{3}$ Dept of Internal Medicine, Genoa University, Genoa, Italy. ${ }^{4}$ Sleep Clinic, National Institute of Respiratory Diseases, Mexico City, Mexico. ${ }^{5}$ VA-CT Clinical Epidemiology Research Center and Yale School of Medicine, West Haven, CT, USA. ${ }^{6}$ Pulmonary and Critical Care Medicine, University of Washington, Seattle, WA, USA. ${ }^{7}$ Respiratory Physiology Laboratory, Christchurch Hospital, Christchurch, New Zealand. ${ }^{8}$ Institute of Occupational and Environmental Medicine, University of Birmingham, Birmingham, UK. ${ }^{9}$ Physiology Service, Allergy Immunology and Respiratory Medicine, The Alfred Hospital, Melbourne, Australia. ${ }^{10}$ Dept of Respiratory Medicine, Allergy and Thoracic Surgery, University Hospitals of Leicester, and Glenfield Hospital, Leicester, UK. ${ }^{11}$ National Heart and Lung Institute, Imperial College London, London, UK. ${ }^{12}$ Division of Respirology, Critical Care and Sleep Medicine, University of Saskatchewan, Saskatoon, SK, Canada. ${ }^{13}$ Centro Medico Pneumologico Torino, Clinica Pinna Pintor, Torino, Italy. ${ }^{14}$ Dept of Medicine, University of Arizona, Tucson, AZ, USA. ${ }^{15}$ Pulmonary \& Critical Care Medicine, Oregon Health \& Science University, Portland, OR, USA. ${ }^{16}$ National Heart and Lung Institute, London, UK.

Correspondence: Philip H Quanjer, Department of Pulmonary Diseases and Department of Paediatrics-Pulmonary Diseases, Erasmus Medical Centre, Erasmus University, Rotterdam, The Netherlands. E-mail: pquanjer@xs4all.nl

Received: Aug 062015 | Accepted after revision: Aug 122015

Conflict of interest: None declared.

\section{References}

1 Celli BR, Decramer M, Wedzicha JA, et al. An official American Thoracic Society/European Respiratory Society Statement: Research questions in COPD. Eur Respir J 2015; 45: 879-905.

2 Celli BR, Decramer M, Wedzicha JA, et al. An Official American Thoracic Society/European Respiratory Society Statement: Research questions in chronic obstructive pulmonary disease. Am J Respir Crit Care Med 2015; 191: e4-e27.

3 Pauwels RA, Buist AS, Calverley PMA, et al. Global strategy for the diagnosis, management, and prevention of chronic obstructive pulmonary disease: NHLBI/WHO Global Initiative for Chronic Obstructive Lung Disease (GOLD) Workshop summary. Am J Respir Crit Care Med 2001; 163: 1256-1276.

4 Quanjer PH, Stanojevic S, Cole TJ, et al. Multi-ethnic reference values for spirometry for the 3-95-yr age range: the global lung function 2012 equations. Eur Respir J 2012; 40: 1324-1343.

5 Vollmer WM, Gislason T, Burney P, et al. Comparison of spirometry criteria for the diagnosis of COPD: results from the BOLD study. Eur Respir J 2009; 34: 588-597.

6 Mannino DM, Doherty DE, Buist AS. Global Initiative on Obstructive Lung Disease (GOLD) classification of lung disease and mortality: findings from the Atherosclerosis Risk in Communities (ARIC) study. Respir Med 2006; 100: 115-122.

7 Ekberg-Aronsson M, Pehrsson K, Nilsson JA, et al. Mortality in GOLD stages of COPD and its dependence on symptoms of chronic bronchitis. Respir Res 2005; 6: 98.

8 Vaz Fragoso CA, Concato J, McAvay G, et al. Chronic obstructive pulmonary disease in older persons: a comparison of two spirometric definitions. Respir Med 2010; 104: 1189-1196.

9 Mannino DM, Buist AS, Vollmer WM. Chronic obstructive pulmonary disease in the older adult: what defines abnormal lung function? Thorax 2007; 62: 237-241.

10 Turkeshi E, Vaes B, Andreeva E, et al. Airflow limitation by the Global Lungs Initiative equations in a cohort of very old adults. Eur Respir J 2015; 46: 123-132.

11 Bridevaux P-O, Gerbase MW, Probst-Hensch NM, et al. Long-term decline in lung function, utilisation of care and quality of life in modified GOLD stage 1 COPD. Thorax 2008; 63: 768-774.

12 Akkermans RP, Berrevoets MA, Smeele IJ, et al. Lung function decline in relation to diagnostic criteria for airflow obstruction in respiratory symptomatic subjects. BMC Pulm Med 2012; 12: 12.

13 Akkermans RP, Biermans M, Robberts $\mathrm{B}$, et al. COPD prognosis in relation to diagnostic criteria for airflow obstruction in smokers. Eur Respir J 2014; 43: 54-63.

14 Pedone C, Scarlata S, Sorino C, et al. Does mild COPD affect prognosis in the elderly? BMC Pulm Med 2010; 10: 35.

15 Vaz Fragoso CA, Concato J, McAvay G, et al. The ratio of FEV1 to FVC as a basis for establishing chronic obstructive pulmonary disease. Am J Respir Crit Care Med 2010; 181: 446-451.

16 Mannino DM, Diaz-Guzman E. Interpreting lung function data using $80 \%$ predicted and fixed thresholds identifies patients at increased risk of mortality. Chest 2012; 141: 73-80.

17 Wollmer P, Engström G. Fixed ratio or lower limit of normal as cut-off value for FEV1/VC: an outcome study. Respir Med 2013; 107: 1460-1462.

18 Enright PL. GOLD stage I is not a COPD risk factor. Thorax 2007; 62: 1107.

19 Miller MR. Lung function data interpretation. Chest 2012; 141: 832-833.

20 Quanjer PH, Cole TJ. COPD and GOLD stage I. Chest 2012; 141: 1122.

21 Vaz Fragoso CA, Pretto J. Comment on: Fixed ratio or lower limit of normal (LLN) as cut-off value for FEV1/VC. Respir Med 2015; 109: 928.

22 Feinstein A. The inadequacy of binary models for the clinical reality of three-zone diagnostic decisions. J Clin Epidemiol 1990; 43: 109-113.

23 Miller MR, Levy ML. Chronic obstructive pulmonary disease: missed diagnosis versus misdiagnosis. BMJ 2015; 351: h3021.

24 Pellegrino R, Viegi G, Brusasco V, et al. Interpretative strategies for lung function tests. Eur Respir J 2005; 26 : 948-968.

25 Global Brief for World Health Day. Geneva, Switzerland, World Health Organization. www.who.int/world-healthday/2012/ Date last accessed: July 25, 2015. 